\title{
Predictive costs in medical care for Koreans with metabolic syndrome from 2009 to 2013 based on the National Health Insurance claims dataset
}

\author{
Jeong Seon $\mathrm{Yoo}^{1,2}$, Eun Yeong Choe ${ }^{2}$, Yoo Mee Kim³ , Se Hwa Kim³, and Young Jun Won ${ }^{3}$
}

1Department of Internal Medicine, Seobuk Hospital, Seoul Metropolitan Government, Seoul; ${ }^{2}$ Graduate School, Yonsei University College of Medicine, Seoul; ${ }^{3}$ Department of Internal Medicine, International St. Mary's Hospital, Catholic Kwandong University College of Medicine, Incheon, Korea

Received: October 27, 2016 Revised : May 12, 2017

Accepted: August 16, 2018

\section{Correspondence to}

\section{Young Jun Won, M.D.}

Department of Internal

Medicine, International St.

Mary's Hospital, Catholic

Kwandong University College

of Medicine, 25 Simgok-ro

roobeon-gil, Seo-gu, Incheon

22711, Korea

Tel: +82-32-290-3963

Fax: +82-32-290-3879

E-mail:yjwonoo@gmail.com
Background/Aims: Although metabolic syndrome has been associated with increasing medical costs worldwide, there have been no studies using a nationwide and longitudinal South Korean dataset. We investigated trends in subsidized medical costs among Korean adults with metabolic syndrome.

Methods: This study was based on the National Sample Cohort database of South Korea. We used data of national health checkups in 2009 as well as data of subsidized prescription drugs and the Korean Classification of Disease diagnosis codes from claims in 2007 to 2008 to identify underlying diseases. We calculated the direct medical costs, which were subsidized by the Korean National Health Insurance, among 204,768 individuals older than 20 years from 2009 to 2013.

Results: The proportion of subjects with metabolic syndrome was $27.2 \%$. Direct medical costs for 5 years differed by a magnitude of 2.16 between subjects with and without metabolic syndrome. The costs increased by approximately $41.8 \%$ in the metabolic syndrome group in 5 years. Direct medical costs increased with every additional risk factor, even if a subject had less than three risk factors of metabolic syndrome. Metabolic syndrome per se and all of its components, except low serum high-density lipoprotein cholesterol level, resulted in a significant increase in medical costs.

Conclusions: The medical costs of subjects with metabolic syndrome were higher than that of those without metabolic syndrome and it increased with the number of risk factors. Further research using cumulative data of more than 10 years, including unsubsidized and indirect costs, is needed in the future.

Keywords: Metabolic syndrome; Direct medical costs; Korea; Korean National Health Insurance

\section{INTRODUCTION}

Metabolic syndrome (MetS) is composed of multiple risk factors including high blood pressure, abdominal obesity, dyslipidemia, and abnormal glucose metabolism. There is no unified definition of MetS [1]. However, all of the above conditions are useful indicators to help identify patients at increased risk for not only cardiovascular disease but also for all-cause mortality [2].

MetS has emerged as a major public health concern worldwide. The prevalence of MetS has increased by more than $25 \%$ in the United States [3]. There have been several studies on medical costs of MetS and related diseases because the economic burden of MetS has been 
greatly increasing. In the Cardiovascular Health Study (CHS), the total costs to Medicare were 20\% higher among participants with MetS than that of those without MetS $[4,5]$. The economic burden of medical care for MetS in patients with hypertension is forecasted to increase by $59 \%, 179 \%$, and $157 \%$ in Germany, Spain, and Italy, respectively, by 2020 [5].

In this global trend, South Korea is no exception. The age-adjusted prevalence of MetS increased sharply from $24.9 \%$ in 1999 to $31.3 \%$ in 2007 according to data from the Korean National Health and Nutrition Examination Survey conducted between 1998 and 2007 [6]. The local government of Seoul has operated public health centers participating in the MetS management program since 2010 [7]. In a cross-sectional study, Kong et al. [8] reported that workers in small-scale enterprises were more likely to have MetS and to spend more on medical costs for major diseases related to MetS. However, nationwide cost analyses of MetS using a longitudinal database are lacking.

The aim of this study was to analyze the direct medical costs of MetS using longitudinal data of the South Korean population and to examine the influence of each component of MetS on medical costs in South Korea.

\section{METHODS}

\section{Statement of ethics}

This study adhered to the tenets of the Declaration of Helsinki and was approved by the Institutional Review Board of Catholic Kwandong University International St. Mary's Hospital, South Korea (IS14EISIoo15). The requirement for written informed consent was waived.

\section{Database}

This study used a retrospective cohort design and included data from the National Sample Cohort database, collected from 2002 to 2013 which was released by the Korean National Health Insurance Service (KNHIS). It is compulsory for all citizens and medical providers in South Korea to participate in the Medical Assistance Program or the Medical Care for Patriots and Veterans Affairs Scheme conducted by the KNHIS. Therefore, a complete enumeration of medical costs, except any unsubsidized costs such as those of cosmetic surgery or novel, unproven treatment, is centralized in the KNHIS databases. Claims submitted by medical providers are accompanied by data, including diagnostic codes, procedures, prescription drugs, personal information of the patient, and direct medical costs of both inpatient and outpatient care. The KNHIS uses the Korean Classification of Diseases (KCD) [9], which is similar to the International Classification of Diseases (ICD).

The KNHIS has managed national health checkup programs biennially for all insured individuals and their dependents since 1980 . Approximately, $66 \%$ of the target population was reported to have participated in these health checkup programs in 2009 [10].

\section{Study sample}

The National Sample Cohort database represented approximately $2.2 \%$ of the entire population in the KNHIS in 2002. The database was sampled systematically to represent the individual total annual medical expenses within each of the 1,476 strata defined by age, sex, employment condition, and income level combinations (n $=46,605,433$ ). Subjects who underwent a national health checkup and were older than 20 years in 2009 were enrolled $(n=204,768)$. Patients who had been treated for cancer (denoted by KCD codes C, corresponding to ICD, 9th Revision, Clinical Modification [ICD-9-CM] codes 140-239) between 2007 and 2008 or who died between 2009 and 2013 were excluded because of a sudden increase in medical care costs near the verge of death and after cancer diagnosis.

\section{Definitions of metabolic syndrome and related diseases}

We defined MetS according to the modified National Cholesterol Education Program-Adult Treatment Panel III criteria, the abdominal obesity criteria of the Korean Society for the Study of Obesity [11], and the usage of anti-hyperlipidemic drugs. The following components were considered:

(1) Abdominal obesity (waist circumference $\geq 90 \mathrm{~cm}$ in men and $\geq 85 \mathrm{~cm}$ in women);

(2) Elevated triglycerides ( $\geq 150 \mathrm{mg} / \mathrm{dL}$ ) or use of anti-hyperlipidemic drugs;

(3) Low level of high density lipoprotein cholesterol $(\mathrm{HDL}-\mathrm{C})(<40 \mathrm{mg} / \mathrm{dL}$ in men and $<50 \mathrm{mg} / \mathrm{dL}$ in women); 
(4) Elevated blood pressure (systolic blood pressure $\geq$ $130 \mathrm{~mm} \mathrm{Hg}$; diastolic blood pressure $\geq 85 \mathrm{mmHg}$ ) or use of antihypertensive drugs;

(5) Elevated fasting plasma glucose levels $(\geq 100 \mathrm{mg} / \mathrm{dL})$ or use of hypoglycemic drugs.

Individuals having three or more of the above components were defined as having MetS.

We used the health checkup data of 2009 because the KNHIS did not include data of waist circumference and HDL-C and triglyceride levels until late 2008. Patients using antihyperglycemic, antihypertensive, and antihyperlipidemic agents were considered to have diabetes mellitus, hypertension, and dyslipidemia, respectively, even though they showed normal clinical values for the associated tests. All diagnosis codes were collected from claims in 2007-2008 for cardiac disorders (KCD codes I2O-25, corresponding to ICD9-CM codes 410-414), stroke (KCD codes I60-169, corresponding to ICD-9-CM codes 430-438), hypertension (KCD codes I10-13, corresponding to ICD-9-CM codes 401-404), dyslipidemia (KCD codes I2O-25 and I60-69, corresponding to ICD-9-CM codes 272.4), and diabetes mellitus (KCD codes E10-14, corresponding to ICD9-CM codes 249-259). The questionnaires of national health checkups were also used to define the underlying diseases of the subjects.

Cardiovascular and cerebrovascular diseases that are not directly related with MetS or have ambiguous definition were not considered in this study. More specifically, cardiac disorders such as valvular heart disease (KCD codes I05-09 and I35-39) and arrhythmia (KCD codes I44-49) and cerebrovascular diseases such as cerebral hemorrhage (KCD codes I6o-62) and cerebral aneurysm (KCD codes I64-69) were excluded.

\section{Lifestyle assessment}

Lifestyle factors like smoking status [12], alcohol consumption [13], and level of physical exercise [14] are associated with MetS. For lifestyle assessment, a health checkup questionnaire that gathered data about smoking, drinking, and exercise status was used [15]. Exercise status was reclassified according to the recommendations of the World Health Organization [16]. Drinking levels were redefined according to the criteria of the National Institute on Alcohol Abuse and Alcoholism [17].
(1) Smoking: Subjects were classified as nonsmokers, past smokers, and current smokers. Nonsmokers were subjects who had never smoked a cigarette. Past smokers were subjects who had smoked but quit prior to 2009. Current smokers were subjects who smoked consistently in 2009 .

(2) Alcohol consumption: Drinking was classified by the frequency of alcohol consumption and the number of glasses of alcohol consumed on each occasion. Nondrinkers were subjects who drank less than once a week and one glass at a time. Social drinkers were subjects who drank one to two times a week and one to four glasses at a time. Heavy drinkers were subjects who drank three or more times a week and five or more glasses at a time.

(3) Exercise status: Physical activity was classified into nonactive and active categories. The nonactive category included subjects who performed $<150 \mathrm{~min}$ utes of moderate-intensity exercise or 75 minutes of vigorous-intensity exercise per week. The active category included subjects who performed $>300$ minutes of moderate-intensity exercise or $150 \mathrm{~min}$ utes of vigorous-intensity exercise per week.

\section{Household income level}

Low income appears to be associated with a high prevalence of MetS [18]. The major sources of KNHIS financing are contributions from insured individuals and from government subsidies. Almost all citizens are registered with and contribute to the KNHIS. Contributions differ according to income and wealth [19]. The National Sample Cohort database classified insured individuals and their dependents into 11 levels according to the amount of contribution [20]. We used their classification as a substitute variable for household income level.

\section{Costs and statistical analysis}

Direct medical costs included the cost of a defined intervention and all follow-up costs including those for other medications and health care interventions in ambulatory, inpatient, and nursing care. Direct non-medical costs included costs for transportation and additional paid caregiver time. Indirect costs included the value of lost output (impairment or disability to work) due to a disease or disorder [21].

We obtained medical claims data from the KNHIS 
Table 1. Comparison of baseline characteristics of the overall study population according to metabolic syndrome status

\begin{tabular}{|c|c|c|c|c|}
\hline \multirow{2}{*}{ Characteristic } & \multirow{2}{*}{ Overall } & \multicolumn{3}{|c|}{ Metabolic syndrome } \\
\hline & & No & Yes & $p$ value \\
\hline No. of subjects & 204,768 & $149,093(78.0)$ & $55,675(22.0)$ & \\
\hline Age, yr & & & & $<0.0001$ \\
\hline $20-44$ & $94,013(45.91)$ & $80,932(54.28)$ & $13,081(23.5)$ & \\
\hline $45-65$ & $85,006(41.51)$ & $56,348(37 \cdot 79)$ & $28,658(51.47)$ & \\
\hline Above 65 & $25,749(12.57)$ & $11,813(7.92)$ & $13,936(25.03)$ & \\
\hline Men & $112,023(54.71)$ & $81,809(54.87)$ & $30,214(54.27)$ & 0.0149 \\
\hline $\mathrm{BMI}, \mathrm{kg} / \mathrm{m}^{2}$ & $23.49(23.48-23.20)$ & $22.75(22.74-22.77)$ & $25.59(25.57-25.62)$ & 0.006 \\
\hline Waist, cm & $79.71(79.67-79.75)$ & $77.38(77.34-77.42)$ & $86.29(86.22-86.36)$ & $<0.0001$ \\
\hline $\mathrm{SBP}, \mathrm{mmHg}$ & $120.60(121.50-121.60)$ & $118.50(118.50-118.60)$ & $130.10(130.00-130.20)$ & $<0.0001$ \\
\hline $\mathrm{DBP}, \mathrm{mmHg}$ & $75.70(75.66-75.74)$ & $74.08(74.03-74.13)$ & $80.21(80.13-80.29)$ & 0.002 \\
\hline $\mathrm{FBG}, \mathrm{mg} / \mathrm{dL}$ & $95.33(95.25-95.40)$ & $91.23(91.17-91.30)$ & $107.20(107.00-107.40)$ & $<0.0001$ \\
\hline $\mathrm{TC}, \mathrm{mg} / \mathrm{dL}$ & $191.90(191.70-192.00)$ & $189.30(189.10-189.50)$ & $199.00(198.60-199.30)$ & $<0.0001$ \\
\hline $\mathrm{TG}, \mathrm{mg} / \mathrm{dL}$ & $112.80(112.60-113.10)$ & $92.52(97.26-97.78)$ & $166.80(166.00-167.60)$ & $<0.0001$ \\
\hline HDL-C, mg/dL & $53.69(53.62-53.76)$ & $56.27(56.19-56.35)$ & $47 \cdot 34(47 \cdot 34-47.46)$ & $<0.0001$ \\
\hline LDL-C, mg/dL & $107.50(107.30-107.60)$ & $107.50(107.30-107.70)$ & $107.40(107.00-107.80)$ & $<0.0001$ \\
\hline $\mathrm{Cr}, \mathrm{mg} / \mathrm{dL}$ & $0.938(0.936-0.940)$ & $0.935(0.933-0.937)$ & $0.945(0.942-0.948)$ & $<0.0001$ \\
\hline AST, mg/dL & $23.39(23.35-23.42)$ & $22.49(22.46-22.53)$ & $25.96(25.88-26.05)$ & $<0.0001$ \\
\hline $\mathrm{ALT}, \mathrm{mg} / \mathrm{dL}$ & $21.29(21.24-21.34)$ & $19.70(19.65-19.75)$ & $26.23(26.11-26.35)$ & $<0.0001$ \\
\hline$\gamma \mathrm{GT}, \mathrm{mg} / \mathrm{dL}$ & $26.35(26.27-26.43)$ & $23.81(23.73-23.90)$ & $34.55(34.33-34.77)$ & $<0.0001$ \\
\hline Hypertension & $42,483(21.77)$ & $14,767(10.48)$ & $27,716(51.13)$ & $<0.0001$ \\
\hline Diabetes mellitus & $30,680(14 \cdot 5)$ & $12,571(7.8)$ & $18,109(36.6)$ & $<0.0001$ \\
\hline Cardiac disorders & $12,992(6.67)$ & $4,492(3.19)$ & $8,500(15 \cdot 71)$ & $<0.0001$ \\
\hline Stroke & $5,049(2.59)$ & $1,578(1.12)$ & $3,471(6.41)$ & $<0.0001$ \\
\hline Smoking status & & & & $<0.0001$ \\
\hline Non-smokers & $119,724(59.91)$ & $87,149(59.86)$ & $32,575(60.06)$ & \\
\hline Past smokers & $27,825(13.92)$ & $19,238(13.21)$ & $8,587(15.83)$ & \\
\hline Current smokers & $52,282(26.16)$ & $39,209(26.93)$ & $13,073(24.01)$ & \\
\hline Alcohol consumption & & & & $<0.0001$ \\
\hline Non-drinkers & $94,919(46.98)$ & $65,151(44.30)$ & $29,768(54.16)$ & \\
\hline Social drinkers & $17,018(8.42)$ & $13,524(9.20)$ & $3,494(6.36)$ & \\
\hline Heavy drinkers & $90,089(44.59)$ & $68,385(46.50)$ & $21,704(39 \cdot 49)$ & \\
\hline Exercise status & & & & $<0.0001$ \\
\hline Non-active & $173,062(86.10)$ & $126,460(86.46)$ & $46,602(85.12)$ & \\
\hline Active & $27,948(13.90)$ & $19,803(13.54)$ & $8,145(14.88)$ & \\
\hline House hold income level & & & & $<0.0001$ \\
\hline $0-3$ & $44,415(21.69)$ & $32,178(21.58)$ & $12,237(21.98)$ & \\
\hline $4-7$ & $83,411(40.74)$ & $63,171(42.37)$ & $20,240(36.35)$ & \\
\hline $8-10$ & $79,942(37.58)$ & $53,744(36.05)$ & $23,198(41.66)$ & \\
\hline \multicolumn{5}{|c|}{ Modified NCEP-ATP III criteria } \\
\hline Abdominal obesity & $47,079(22.99)$ & $15,241(10.22)$ & $31,838(57.19)$ & $<0.0001$ \\
\hline Hypertriglyceridemia & $82,340(40.21)$ & $35,172(23.59)$ & $47,168(84.72)$ & $<0.0001$ \\
\hline Low HDL-C level & $41,661(20.35)$ & $17,287(11.59)$ & $24,374(43.78)$ & $<0.0001$ \\
\hline High blood pressure & $97,795(47.76)$ & $49,061(32.91)$ & $48,734(87 \cdot 53)$ & $<0.0001$ \\
\hline Hyperglycemia & $71,550(34.94)$ & $30,580(20.51)$ & $40,970(73.59)$ & $<0.0001$ \\
\hline
\end{tabular}

Values are presented as number (\%) or geometric mean (95\% confidence interval). Percentages may not sum to $100 \%$ because of missing data. Abdominal obesity, waist circumference $\geq 90 \mathrm{~cm}$ in men and $\geq 85 \mathrm{~cm}$ in women; hypertriglyceridemia, serum triglyceride $\geq 150$ $\mathrm{mg} / \mathrm{dL}$; low HDL-C level, HDL-C < $40 \mathrm{mg} / \mathrm{dL}$ in men and < $50 \mathrm{mg} / \mathrm{dL}$ in women; high blood pressure, blood pressure $\geq 130 / 85 \mathrm{mmHg}$ or current use of antihypertensive medication; hyperglycemia, serum glucose $\geq 100 \mathrm{mg} / \mathrm{dL}$ or current use of medication for diabetes. BMI, body mass index; SBP, systolic blood pressure; DBP, diastolic blood pressure; FBG, fasting blood glucose; TC, total cholesterol; TG, triglyceride; HDL-C, high density lipoprotein cholesterol; LDL-C, low density lipoprotein cholesterol; Cr, creatinine; AST, aspartate transaminase; ALT, alanine aminotransferase; $\gamma$ GT, gamma-glutamyl transpeptidase; NCEP-ATP, National Cholesterol Education Program-Adult Treatment Panel. 
to describe direct medical costs, including inpatient, outpatient, laboratory, and pharmacy utilization, which covered all subsidized medical services of medical institutions, pharmacies, and dental and oriental medicine clinics, for each subject from 2009 to 2013. Patient copayments and deductibles were included in the direct medical costs.

These costs were valued in 2013 Korean won [22] and then converted to US dollar (USD) according to the exchange rate in 2009 to 2013 ( 1 USD = 1,152 Korean won) [23].

Descriptive statistics of the study population at baseline were presented using numbers and frequencies for categorical variables and using geometric means with standard deviations (SD) for continuous variables. Student's $t$ tests were performed to compare continuous variables. The chi-square test and analysis of variance were performed for comparing between categorical variables of the two groups. Medical costs were presented as unadjusted means with standard errors.

We used generalized linear mixed models to analyze trends of direct medical costs on a yearly basis or by the number of MetS components. Simple and multiple regression models were used to assess the independent contributions of each MetS component. We used SAS version 9.4 (SAS Institute, Cary, NC, USA) for all analyses, and $p<0.05$ was considered to be statistically significant.

\section{RESULTS}

\section{Baseline characteristics}

Characteristics of subjects at baseline are listed in Table 1. Twenty-two percent of the subjects met the modified National Cholesterol Education Program-Adult Treatment Panel III criteria for MetS. The proportion of subjects older than 65 years was higher in the MetS group than in the non-MetS group. The number of men was slightly higher than the number of women in the MetS group. As expected, the subjects with MetS were more likely to have high blood pressure, high levels of fasting blood glucose and triglycerides, greater waist circumference, and low levels of HDL-C than subjects without MetS. Among the parameters evaluated using blood test, serum creatinine level, which reflects renal function, was the only parameter that was not significantly different between the two groups $(p=0.336)$. Furthermore, subjects with MetS had a higher chance of having hypertension, diabetes mellitus, cardiac disorders, and stroke than those without MetS. Subjects without MetS were more physically active. Unexpectedly, subjects in the MetS group were less likely to smoke or drink alcohol, compared to non-MetS group. Furthermore, subjects with MetS had higher house-hold income than those without MetS. Similar patterns were observed after stratification by sex (Supplementary Tables 1 and 2).

\section{The direct medical costs of metabolic syndrome}

Fig. 1 shows the direct medical costs subsidized by the KNHIS from 2009 to 2013. The direct medical costs of subjects with MetS for 5 years were 2.16 times higher than that of those without MetS. Women and older individuals spent more than males and young individuals, respectively, in both groups in total and in each year. The annual costs increased consistently in 5 years in both groups (Fig. 2). The intra- and inter-group differences of yearly costs were significant $(p<0.001)$.

\section{The influence of metabolic syndrome components on medical costs}

Fig. 3 shows annual costs according to the number of MetS components. The medical care costs incurred over 5 years increased with each additional MetS component present. Presence of every additional risk factor resulted in a significant increase in medical costs $(p<0.05)$, even if the patient had less than three of the mentioned MetS components.

Table 2 shows the results of the simple and multiple regression models. In models I to VI, we examined how much the cost increased by each MetS component using the simple regression model. MetS and all five of its components were significantly associated with higher medical costs over the 5 years. Even after controlling for age, sex, household income level, smoking status, drinking level, and exercise status, MetS and each of its components had incurred more medical costs, except low HDL-C level $(p=0.601)$. The parameter estimates of each component ranged from 1,335 USD for abdominal obesity to 2,401 USD for MetS per se in multiple regression models I to VI. When we analyzed the effects of multiple risk factors simultaneously using model VII, the parameter estimates decreased but remained highly sta- 
(\$)

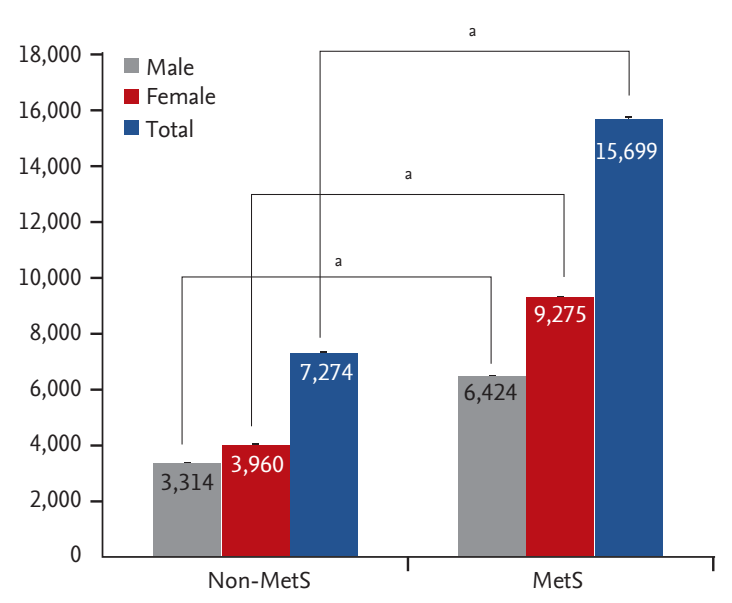

(\$)

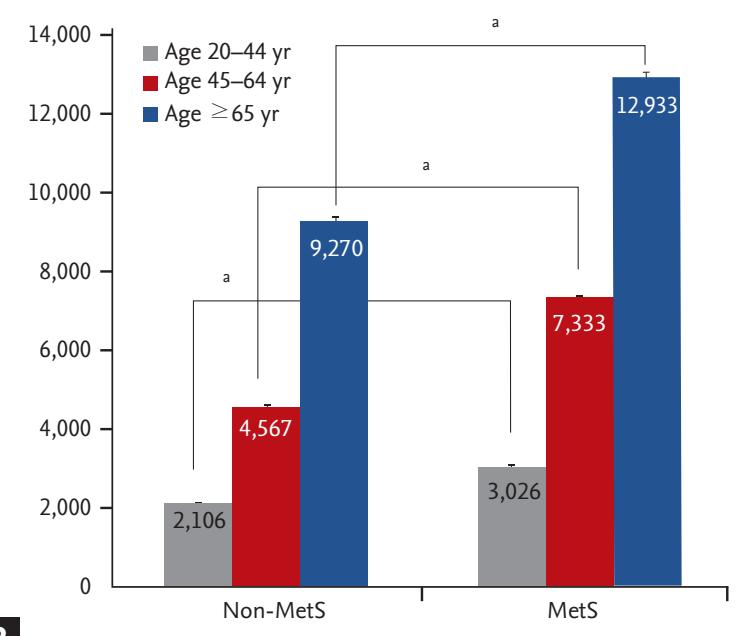

B

Figure 1. Direct medical costs of subjects with or without metabolic syndrome (MetS) for 5 years, stratified by (A) sex and (B) age. Data are unadjusted mean \pm standard error. ${ }^{\mathrm{a}} p<0.001$.

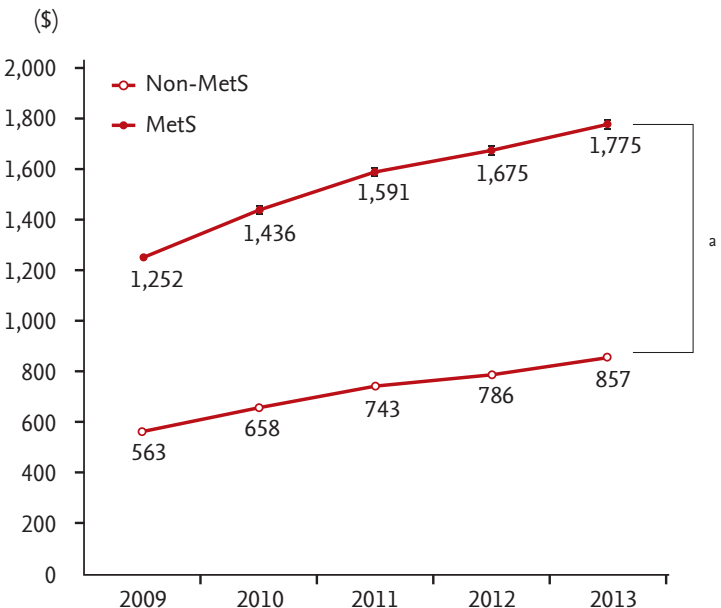

Figure 2. Direct medical costs per each year per person with and without metabolic syndrome (MetS). Data are unadjusted mean \pm standard error. ${ }^{a} p<0.05$.

tistically significant $(p<0.001$ for all components except $p=0.485$ for low HDL-C level). After further adjustment for cardiac disorders and stroke in the multiple regression model VIII, a modest but not significant decrease was observed in the size of estimates for MetS per se and for each component. After stratifying by sex, low HDL-C level was statistically significant but had no economic impact (Supplementary Tables 3 and 4).

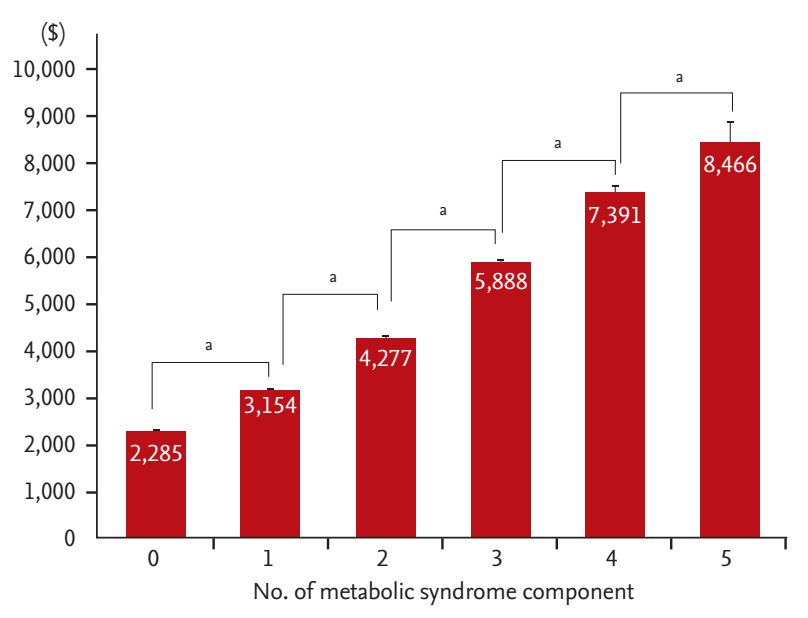

Figure 3. Direct medical over 5 years by the number of metabolic syndrome (MestS) components present at baseline. ${ }^{\mathrm{a}} \mathrm{p}<0.001$.

\section{DISCUSSION}

In this retrospective cohort study, we found that the direct medical costs subsidized by the KNHIS were associated with MetS per se and with each of its components during a 5-year period. There have been several studies investigating the relationship between medical costs and MetS. However, they either covered only an age 
Table 2. Predictive costs of metabolic syndrome and its components between 2009 and 2013

\begin{tabular}{|c|c|c|c|c|c|c|c|c|}
\hline \multirow[b]{2}{*}{ Variable } & \multicolumn{2}{|c|}{ Simple regression model } & \multicolumn{2}{|c|}{$\begin{array}{l}\text { Multiple regression } \\
\text { models I through VI }\end{array}$} & \multicolumn{2}{|c|}{$\begin{array}{c}\text { Multiple regression } \\
\text { model VII }\end{array}$} & \multicolumn{2}{|c|}{$\begin{array}{l}\text { Multiple regression } \\
\text { model VIII }\end{array}$} \\
\hline & $\begin{array}{l}\text { Parameter } \\
\text { estimation, } \\
\text { USD }\end{array}$ & $p$ value & $\begin{array}{c}\text { Parameter } \\
\text { estimation, } \\
\text { USD }\end{array}$ & $p$ value & $\begin{array}{c}\text { Parameter } \\
\text { estimation, } \\
\text { USD }\end{array}$ & $p$ value & $\begin{array}{c}\text { Parameter } \\
\text { estimation, } \\
\text { USD }\end{array}$ & $p$ value \\
\hline Metabolic syndrome & 4,123 & $<0.001$ & 2,401 & $<0.001$ & 850 & $<0.001$ & 561 & $<0.001$ \\
\hline Abdominal obesity & 2,818 & $<0.001$ & 1,335 & $<0.001$ & 422 & $<0.001$ & 487 & $<0.001$ \\
\hline Hypertriglyceridemia & 2,401 & $<0.001$ & 1,529 & $<0.001$ & 701 & $<0.001$ & 557 & $<0.001$ \\
\hline Low HDL-C level & 1,588 & $<0.001$ & 581 & 0.601 & 33 & 0.485 & 29 & 0.549 \\
\hline High blood pressure & 3,397 & $<0.001$ & 1,833 & $<0.001$ & 1,182 & $<0.001$ & 1,033 & $<0.001$ \\
\hline Hyperglycemia & 2,736 & $<0.001$ & 1,512 & $<0.001$ & 803 & $<0.001$ & 750 & $<0.001$ \\
\hline Age & 4,147 & $<0.001$ & a & $<0.001$ & 3,200 & $<0.001$ & 2,966 & $<0.001$ \\
\hline Female gender & 1,267 & $<0.001$ & $\mathrm{~b}$ & $<0.001$ & 706 & $<0.001$ & 667 & $<0.001$ \\
\hline Intercept & - & - & c & $<0.001$ & $-2,425$ & $<0.001$ & $-2,031$ & $<0.001$ \\
\hline Cardiac disorders & - & - & - & - & - & - & 3,069 & $<0.001$ \\
\hline Stroke & - & - & - & - & - & - & 4,145 & $<0.001$ \\
\hline
\end{tabular}

Multiple regressions models I through VI include age, sex, household income level, smoking status, drinking level, exercise status, and each individual metabolic syndrome component. Multiple regression model VII includes all components of metabolic syndrome and controls for age, sex, household income level, smoking status, drinking level, and exercise status. Multiple regression model VIII adds controls for cardiac disorders and stroke to model VII. Abdominal obesity, waist circumference $\geq 90 \mathrm{~cm}$ in men and $\geq 85 \mathrm{~cm}$ in women; hypertriglyceridemia, serum triglyceride $\geq 150 \mathrm{mg} / \mathrm{dL}$; low HDL-C level, HDL-C < 40 $\mathrm{mg} / \mathrm{dL}$ in men and $<50 \mathrm{mg} / \mathrm{dL}$ in women; high blood pressure, blood pressure $\geq 130 / 85 \mathrm{mmHg}$ or current use of antihypertensive medication; hyperglycemia, serum glucose $\geq 100 \mathrm{mg} / \mathrm{dL}$ or current use of medication for diabetes.

USD, US dollar; HDL-C, high density lipoprotein cholesterol.

${ }^{a}$ Individual parameter estimates for age were as follows: model I (metabolic syndrome [MetS]), 3,493 USD; model II (abdominal obesity), 3,814 USD; model III (hypertriglyceridemia), 3,749 USD; model IV (low HDL-C), 3,951 USD; model V (high blood pressure), 1,833 USD; and model VI (hyperglycemia), 3,711 USD.

${ }^{\mathrm{b}}$ Individual parameter estimates for female gender were as follows: model I (MetS), 440 USD; model II (abdominal obesity), 269 USD; model III (hypertriglyceridemia), 596 USD; model IV (low HDL-C), 348 USD; model V (high blood pressure), 670 USD; and model VI (hyperglycemia), 565 USD.

${ }^{\mathrm{c}}$ Individual intercepts were as follows: model I (MetS), -1,818 USD; model II (abdominal obesity), -1,818 USD; model III (hypertriglyceridemia), -2,355 USD; model IV (low HDL-C), -2,013 USD; model V (high blood pressure), -2,412 USD; and model VI (hyperglycemia), $-2,263$ USD.

group and region $[4,8,24]$ or were cross-sectional studies $[8,25]$. To our knowledge, this is the first study using a nationwide and longitudinal database in South Korea.

Our results are consistent with those of previous studies examining the impact of MetS and its components on medical costs. However, the specific figures are somewhat different. In the CHS, total costs to Medicare were $20 \%$ higher among participants with MetS than among those without MetS (40,873 USD vs. 33,010 USD, $p$ $<0.001$ ) [4]. Korean workers with MetS paid a minimum of 2.0 times to a maximum of 16.4 times more than those without MetS for treatment of major diseases related to
MetS [8]. In our study that covers both study populations, subsidized medical costs between the two groups differed by a magnitude of 2.61. The conjectured reasons are that the difference in costs is reduced with age and that the study of Korean workers excluded the costs unrelated to MetS. Boudreau et al. [25] found that total costs increased by an average of $24 \%$ per additional risk factor $(p<0.001)$. The average rate of increase was $30.6 \%$ per additional risk factor in our study $(p<0.001)$. We attributed this difference to our study population that had more subjects with cardiac disorders in the MetS group than in the non-MetS group (15.7\% vs. 9.1\%). In fact, an- 
other study, in which the proportion of subjects with cardiac disorders in the MetS group was $17.6 \%$, found an approximate $60 \%$ increase in medical costs per additional risk factor [24].

The results of previous studies have been inconsistent regarding the association between medical costs and MetS components. In the CHS, abdominal obesity, low HDL-C level, and elevated blood pressure, but not MetS per se, were independent predictors of cost in the Medicare population [4]. While an impaired level of fasting glucose was not significantly and positively associated with high annual costs in a study of Kaiser Permanente Northwest (KPNW) members, high triglyceride levels were associated with high annual costs [24]. However, in our study, MetS and its five components were important predictors of medical costs, but low HDL-C level was not associated with high costs after a full adjustment (Table 2). In our opinion, it is because no specific medication is prescribed for low HDL-C level. Furthermore, the diagnosis of low HDL-C level can push patients towards a healthier life style, and that offsets the additional medical expenses. In fact, subjects in the MetS group were less likely to smoke or drink alcohol than those in the non-MetS group (Table 1). Even female subjects with low HDL-C levels paid lesser for medical expenses than females with normal HDL-C levels; however, this difference was too small to be economically meaningful (Supplementary Table 3). This is not relevant to the investigation of KPNW members because it excluded subjects with prior evidence of diabetes mellitus or any of the MetS components during the 2 years before the index year [24]. In the CHS, the researchers reported that unmeasured factors that are important to define "metabolically healthy" status in the elderly population, such as presence of sarcopenia, would have affected their results.

This study has several limitations. First, direct medical costs unsubsidized by the KNHIS and indirect costs such as transportation fees were excluded because the KNHIS only collected the data about the costs that were claimed. According to the Healthcare Bigdata Hub, $97.6 \%$ of the direct medical costs, as judged by the Health Insurance Review and Assessment Service of Korea, were claimed from the KNHIS, and the rest were claimed from private care insurance companies during 2014. The medical costs not examined by the Health
Insurance Review and Assessment Service accounted for $44.7 \%$ of the total medical costs [26]. Therefore, we assumed that subjects with MetS spent approximately 15,235 USD more than those without MetS, including for items unsubsidized by the KNHIS, for 5 years. Second, because we only included subjects who had participated in a national health checkup in 2009, the number of young individuals was high in this study; this is because retired individuals are not forced to participate in regular health checkups as they are typically not employed. However, no other datasets have included a wider range of population than the National Sample Cohort database in South Korea. Third, a follow-up period of 5 years is relatively short to observe a trend in MetS-related costs. Because the national health checkup did not collect data on waist circumference, and triglyceride and HDL-C levels until late 2008 , we necessarily discarded the medical cost data collected from 2002 to 2008 . Fourth, we did not use the whole health checkup data from 2009 to 2013 because not all subjects had the health checkup regularly. Of the subjects, $32.89 \%$ underwent health checkups less than three times during the 5 years.

Our study had multiple strengths. The availability of data for all five components of MetS enabled us to accurately evaluate the economic impact of each MetS component. Nichols and Moler [24] substituted waist circumference with body mass index in their study because waist circumference was rarely measured or recorded in their medical records. Furthermore, we used data of prescription drugs with all disease codes for supplementing the health checkup data. Many studies in South Korea have only used the first two disease codes for convenience and also, did not use the data of prescription drugs $[27,28]$. Thus, we believe that our methods to identify subjects with MetS were sufficiently accurate. Other strengths of our study include the largest sample size studied in South Korea so far and the use of a longitudinal study design.

In conclusion, we found that the presence of MetS and each of its components was associated with high medical costs, even after adjustment with several variables. Future research should include direct health care expenses that are not subsidized by the KNHIS and all indirect medical costs, so that the financial impact of programs that prevent or treat MetS can be calculated correctly. 


\section{KEY MESSAGE}

1. Metabolic syndrome, by itself, and each of its components were associated with high medical costs.

2. Healthcare professionals working in public health should try to reduce the medical costs on metabolic syndrome.

3. The national health system to prevent the metabolic syndrome should be established and provided.

\section{Conflict of interest}

No potential conflict of interest relevant to this article was reported.

\section{Acknowledgments}

We would like to express our gratitude to Jae Hyun Han, Associate Professor at Kwangwoon University College of Business, for advice on statistical analysis that greatly improved the manuscript.

\section{REFERENCES}

1. Grundy SM, Brewer HB Jr, Cleeman JI, et al. Definition of metabolic syndrome: report of the National Heart, Lung, and Blood Institute/American Heart Association conference on scientific issues related to definition. Circulation 2004;109:433-438.

2. Isomaa B, Almgren P, Tuomi T, et al. Cardiovascular morbidity and mortality associated with the metabolic syndrome. Diabetes Care 2001;24:683-689.

3. McCullough AJ. Epidemiology of the metabolic syndrome in the USA. J Dig Dis 2011;12:333-340.

4. Curtis LH, Hammill BG, Bethel MA, Anstrom KJ, Gottdiener JS, Schulman KA. Costs of the metabolic syndrome in elderly individuals: findings from the Cardiovascular Health Study. Diabetes Care 2007;30:2553-2558.

5. Scholze J, Alegria E, Ferri C, et al. Epidemiological and economic burden of metabolic syndrome and its consequences in patients with hypertension in Germany, Spain and Italy: a prevalence-based model. BMC Public Health 2010;10:529.

6. Lim S, Shin H, Song JH, et al. Increasing prevalence of metabolic syndrome in Korea: the Korean National
Health and Nutrition Examination Survey for 1998-2007. Diabetes Care 2011;34:1323-1328.

7. Kim HS, Yoon SJ, Lee KS, et al. Effects of a self-management program for metabolic syndrome: a metabolic syndrome management program in Seoul. Korean J Health Educ Promot 2011;28:51-62.

8. Kong HS, Lee KS, Yim ES, et al. Factors associated with metabolic syndrome and related medical costs by the scale of enterprise in Korea. Ann Occup Environ Med 2013;25:23.

9. Statistical Korea. Statistics Classification Portal [Internet]. Daejeon (KR): Statistical Korea, c1996 [cited 2019 Jul 1]. Available from: http://kssc.kostat.go.kr/ksscNew_web/ index.jsp.

10. Cho B, Lee CM. Current situation of national health screening systems in Korea. J Korean Med Assoc 2011;54:666-669.

11. Lee SY, Park HS, Kim DJ, et al. Appropriate waist circumference cutoff points for central obesity in Korean adults. Diabetes Res Clin Pract 2007;75:72-80.

12. Hwang GY, Cho YJ, Chung RH, Kim SH. The relationship between smoking level and metabolic syndrome in male health check-up examinees over 40 years of age. Korean J Fam Med 2014;35:219-226.

13. Kim SK, Hong SH, Chung JH, Cho KB. Association between alcohol consumption and metabolic syndrome in a community-based cohort of Korean Adults. Med Sci Monit 2017;23:2104-2110.

14. Carroll S, Dudfield M. What is the relationship between exercise and metabolic abnormalities? A review of the metabolic syndrome. Sports Med 2004;34:371-418.

15. National Health Insurance Corporation. Manual of the Regular Health Checkup. Seoul (KR): NHIC, 2009.

16. World Health Organization. WHO Guidelines Approved by the Guidelines Review Committee. Geneva $(\mathrm{CH})$ : WHO, 2010.

17. US Department of Health and Human Services. National Institute on Alcohol Abuse and Alcoholism. Helping Patients Who Drink Too Much: A Clinician's Guide. Updated 2005 ed. Bethesda (MD): National Institutes of Health, 2007.

18. Lee H, Kim BH. Physical activity disparities by socioeconomic status among metabolic syndrome patients: the Fifth Korea National Health and Nutrition Examination Survey. J Exerc Rehabil 2016;12:10-14.

19. National Health Insurance Corporation. National Health Screening Statistical Yearbook 2009. Seoul (KR): NHIC, 
2010.

20. Lee J, Lee JS, Park SH, Shin SA, Kim K. Cohort profile: the National Health Insurance Service-National Sample Cohort (NHIS-NSC), South Korea. Int J Epidemiol 2017;46:e15.

21. Kirch W. Encyclopedia of Public Health. Amsterdam (NL): Springer Netherlands, 2008.

22. Statistics Korea. Easy consumer price index [Internet]. Daejeon (KR): Statistics Korea, c2009 [cited 2019 Jul 1]. Available from: http://kostat.go.kr/incomeNcpi/cpi/index. action.

23. Korean Statistical Information Service. Exchange rate [Internet]. Daejeon (KR): Statistics Korea, c2009 [cited 2019 Jul 1]. Available from: http://kosis.kr.

24. Nichols GA, Moler EJ. Metabolic syndrome components are associated with future medical costs independent of cardiovascular hospitalization and incident diabetes. Me- tab Syndr Relat Disord 2011;9:127-133.

25. Boudreau DM, Malone DC, Raebel MA, et al. Health care utilization and costs by metabolic syndrome risk factors. Metab Syndr Relat Disord 2009;7:305-314.

26. Ministry of Health and Welfare, Yonsei Institute of Health and Welfare, Korea Institute for Health and Social Affairs. Korean National Health Accounts and Total Health Expenditure in 2013. Seoul (KR): Ministry of Health and Welfare, 2015.

27. Lim SJ, Kim HJ, Nam CM, et al. Socioeconomic costs of stroke in Korea: estimated from the Korea national health insurance claims database. J Prev Med Public Health 2009;42:251-260.

28. Kim SY, Yoon SJ, Jo MW, Kim EJ, Kim HJ, Oh IH. Economic burden of allergic rhinitis in Korea. Am J Rhinol Allergy 2010;24:e110-e113. 
Supplementary Table 1. Baseline characteristics and metabolic syndrome status of male subjects

\begin{tabular}{|c|c|c|c|c|}
\hline \multirow{2}{*}{ Characteristic } & \multirow{2}{*}{ Overall } & \multicolumn{3}{|c|}{ Metabolic syndrome } \\
\hline & & No & Yes & $p$ value \\
\hline No. of subjects & 112,023 & $81,809(73.0)$ & $30,214(27.0)$ & \\
\hline Age group, yr & & & & $<0.001$ \\
\hline $20-44$ & $56,932(50.82)$ & $46,566(56.92)$ & $10,366(34 \cdot 31)$ & \\
\hline $45-65$ & $43,499(38.83)$ & $28,644(35.01)$ & $14,855(49 \cdot 17)$ & \\
\hline Above 65 & $11,592(10.35)$ & $6,599(8.07)$ & $4,993(16.53)$ & \\
\hline BMI, $\mathrm{kg} / \mathrm{m}^{2}$ & $24.15 \pm 3.05$ & $23.47 \pm 2.74$ & $25.98 \pm 3.11$ & $<0.001$ \\
\hline Waist, cm & $83.60 \pm 7.79$ & $81.56 \pm 6.77$ & $89.14 \pm 7.66$ & $<0.001$ \\
\hline $\mathrm{SBP}, \mathrm{mmHg}$ & $124.75 \pm 14.08$ & $122.13 \pm 13.17$ & $131.84 \pm 14.03$ & $<0.001$ \\
\hline $\mathrm{DBP}, \mathrm{mmHg}$ & $78.13 \pm 9.74$ & $76.62 \pm 9.23$ & $82.23 \pm 9.90$ & $<0.001$ \\
\hline FBG, $\mathrm{mg} / \mathrm{dL}$ & $99.17 \pm 25.72$ & $93.92 \pm 18.56$ & $113.38 \pm 35.27$ & $<0.001$ \\
\hline $\mathrm{TC}, \mathrm{mg} / \mathrm{dL}$ & $194.79 \pm 36.29$ & $192.79 \pm 34.63$ & $200.18 \pm 39.97$ & $<0.001$ \\
\hline $\mathrm{TG}, \mathrm{mg} / \mathrm{dL}$ & $154.7 \pm 108.51$ & $55.94 \pm 33.03$ & $48.21 \pm 29.12$ & $<0.001$ \\
\hline HDL-C, mg/dL & $53.9 \pm 32.20$ & $113.27 \pm 39.89$ & $110.30 \pm 43.45$ & $<0.001$ \\
\hline LDL-C, mg/dL & $112.5 \pm 40.90$ & $1.28 \pm 1.59$ & $1.28 \pm 1.53$ & $<0.001$ \\
\hline $\mathrm{Cr}, \mathrm{mg} / \mathrm{dL}$ & $1.3 \pm 1.58$ & $26.19 \pm 17.29$ & $30.77 \pm 21.410$ & 0.627 \\
\hline AST, mg/dL & $27.4 \pm 18.60$ & $27.50 \pm 22.66$ & $36.77 \pm 27.75$ & $<0.001$ \\
\hline ALT, mg/dL & $30.0 \pm 24.48$ & $42.78 \pm 50.69$ & $67.65 \pm 82.07$ & $<0.001$ \\
\hline$\gamma \mathrm{GT}, \mathrm{mg} / \mathrm{dL}$ & $49.5 \pm 61.76$ & $55.94 \pm 33.03$ & $48.21 \pm 29.12$ & $<0.001$ \\
\hline Hypertension & $22,089(21.16)$ & $31,916(54.29)$ & $26,869(45 \cdot 71)$ & $<0.001$ \\
\hline Diabetes mellitus & $12,672(38.68)$ & $19,763(45 \cdot 61)$ & $23,570(54.39)$ & $<0.001$ \\
\hline Cardiac disorders & $6,863(6.58)$ & $2,592(3.44)$ & $4,271(14.77)$ & $<0.001$ \\
\hline Stroke & $2,766(2.65)$ & $950(1.26)$ & $1,816(6.28)$ & $<0.001$ \\
\hline Smoking status & & & & $<0.001$ \\
\hline Non-smokers & $32,711(30.18)$ & $24,195(30.52)$ & $8,516(29.28)$ & \\
\hline Past smokers & $26,416(24.38)$ & $18,140(22.88)$ & $8,276(28.45)$ & \\
\hline Current smokers & $49,242(45 \cdot 44)$ & $36,946(46.60)$ & $12,296(42.27)$ & \\
\hline Alcohol consumption & & & & $<0.001$ \\
\hline Non-drinkers & $30,630(27.65)$ & $21,798(26.96)$ & $8,832(29 \cdot 53)$ & \\
\hline Social drinkers & $7,570(6.83)$ & $5,730(7.09)$ & $1,840(6.15)$ & \\
\hline Heavy drinkers & $72,573(65.52)$ & $53,333(65.96)$ & $19,240(64.32)$ & \\
\hline Exercise status & & & & $<0.001$ \\
\hline Non-active & $92,959(84.73)$ & $68,084(85.04)$ & $24,875(83.91)$ & \\
\hline Active & $16,749(15.27)$ & $11,979(14.96)$ & $4,770(16.09)$ & \\
\hline House hold income level & & & & $<0.001$ \\
\hline $0-3$ & $17,855(15 \cdot 94)$ & $12,319(15.06)$ & $5,536(18.32)$ & \\
\hline $4-7$ & $46,673(41.66)$ & $35,346(43.21)$ & $11,327(37.49)$ & \\
\hline $8-10$ & $65,350(58.34)$ & $34,144(41.74)$ & $13,351(44.19)$ & \\
\hline \multicolumn{5}{|c|}{ Modified NCEP-ATP III criteria } \\
\hline Abdominal obesity & $19,686(17.57)$ & $5,688(6.95)$ & $13,998(46.33)$ & $<0.001$ \\
\hline Hypertriglyceridemia & $52,396(46.77)$ & $25,200(30.80)$ & $27,196(90.01)$ & $<0.001$ \\
\hline Low HDL-C level & $16,028(14.31)$ & $5,855(7.16)$ & $10,173(33.67)$ & $<0.001$ \\
\hline High blood pressure & $52,396(46.77)$ & $31,916(39.01)$ & $26,869(88.93)$ & $<0.001$ \\
\hline Hyperglycemia & $43,333(38.68)$ & $19,763(24.16)$ & $23,570(78.01)$ & $<0.001$ \\
\hline
\end{tabular}

Values are presented as number (\%) or geometric mean \pm SD. Percentages may not sum to $100 \%$ because of missing data. Abdominal obesity, waist circumference $\geq 90 \mathrm{~cm}$ in men and $\geq 85 \mathrm{~cm}$ in women; hypertriglyceridemia, serum triglyceride $\geq 150 \mathrm{mg} / \mathrm{dL}$; low HDL-C level, HDL-C $<40 \mathrm{mg} / \mathrm{dL}$ in men and $<50 \mathrm{mg} / \mathrm{dL}$ in women; high blood pressure, blood pressure $\geq 130 / 85 \mathrm{mmHg}$ or current use of antihypertensive medication; hyperglycemia, serum glucose $\geq 100 \mathrm{mg} / \mathrm{dL}$ or current use of medication for diabetes. BMI, body mass index; SBP, systolic blood pressure; DBP, diastolic blood pressure; FBG, fasting blood glucose; TC, total cholesterol; TG, triglyceride; HDL-C, high density lipoprotein cholesterol; LDL-C, low density lipoprotein cholesterol; Cr, creatinine; AST, aspartate transaminase; ALT, alanine aminotransferase; $\gamma$ GT, gamma-glutamyl transpeptidase; NCEP-ATP, National Cholesterol Education Program-Adult Treatment Panel. 
Supplementary Table 2. Baseline characteristics and metabolic syndrome status of female subjects

\begin{tabular}{|c|c|c|c|c|}
\hline \multirow{2}{*}{ Characteristic } & \multirow{2}{*}{ Overall } & \multicolumn{3}{|c|}{ Metabolic syndrome } \\
\hline & & No & Yes & $p$ value \\
\hline No. of subjects & 92,745 & $67,284(72.55)$ & $25,461(27.45)$ & \\
\hline Age group, yr & & & & $<0.001$ \\
\hline $20-44$ & $37,081(39.98)$ & $34,366(51.08)$ & $2,715(10.66)$ & \\
\hline $45-65$ & $41,507(44.75)$ & $27,704(41.17)$ & $13,803(54.21)$ & \\
\hline Above 65 & $14,157(15.26)$ & $5,214(7.75)$ & $8,943(35.12)$ & \\
\hline $\mathrm{BMI}, \mathrm{kg} / \mathrm{m}^{2}$ & $23.17 \pm 3.34$ & $22.27 \pm 2.89$ & $25.56 \pm 3.29$ & $<0.001$ \\
\hline Waist, cm & $76.14 \pm 8.89$ & $73.25 \pm 7.40$ & $83.76 \pm 7.91$ & $<0.001$ \\
\hline $\mathrm{SBP}, \mathrm{mmHg}$ & $119.72 \pm 15.63$ & $115.90 \pm 13.78$ & $129.82 \pm 15.75$ & $<0.001$ \\
\hline $\mathrm{DBP}, \mathrm{mmHg}$ & $74.21 \pm 10.03$ & $72.32 \pm 9.29$ & $79.20 \pm 10.18$ & $<0.001$ \\
\hline FBG, mg/dL & $95.10 \pm 21.44$ & $90.43 \pm 13.89$ & $107.41 \pm 30.90$ & $<0.001$ \\
\hline $\mathrm{TC}, \mathrm{mg} / \mathrm{dL}$ & $195.85 \pm 37.54$ & $191.90 \pm 35.39$ & $206.27 \pm 40.91$ & $<0.001$ \\
\hline $\mathrm{TG}, \mathrm{mg} / \mathrm{dL}$ & $111.86 \pm 74.42$ & $91.88 \pm 52.94$ & $164.67 \pm 94.47$ & $<0.001$ \\
\hline HDL-C, mg/dL & $60.10 \pm 33.63$ & $63.00 \pm 33.78$ & $52.44 \pm 32.02$ & $<0.001$ \\
\hline LDL-C, mg/dL & $115 \cdot 50 \pm 39 \cdot 72$ & $112.74 \pm 38.66$ & $122.79 \pm 41.51$ & $<0.001$ \\
\hline $\mathrm{Cr}, \mathrm{mg} / \mathrm{dL}$ & $0.92 \pm 1.00$ & $0.92 \pm 1.03$ & $0.91 \pm 0.94$ & 0.668 \\
\hline $\mathrm{AST}, \mathrm{mg} / \mathrm{dL}$ & $22.90 \pm 13.15$ & $21.75 \pm 11.62$ & $25.93 \pm 16.13$ & $<0.001$ \\
\hline ALT, mg/dL & $19.97 \pm 18.04$ & $18.05 \pm 16.17$ & $25.05 \pm 21.41$ & $<0.001$ \\
\hline$\gamma \mathrm{GT}, \mathrm{mg} / \mathrm{dL}$ & $22.04 \pm 24.95$ & $19.45 \pm 19.77$ & $28.89 \pm 34.20$ & $<0.001$ \\
\hline Hypertension & $20,394(22.48)$ & $6,131(9.36)$ & $14,263(56.56)$ & $<0.001$ \\
\hline Diabetes mellitus & $10,757(11.86)$ & $2,191(3.35)$ & $8,566(33.98)$ & $<0.001$ \\
\hline Cardiac disorders & $6,129(6.76)$ & $1,900(2.90)$ & $4,229(16.78)$ & $<0.001$ \\
\hline Stroke & $2,283(2.52)$ & $628(0.96)$ & $1,655(6.57)$ & $<0.001$ \\
\hline Smoking status & & & & $<0.001$ \\
\hline Non-smokers & $87,013(95.14)$ & $62,954(94.93)$ & $24,059(95.67)$ & \\
\hline Past smokers & $1,409(1.54)$ & $1,098(1.66)$ & $311(1.24)$ & \\
\hline Current smokers & $3,040(3.32)$ & $2,263(3.41)$ & $777(3.09)$ & \\
\hline Alcohol consumption & & & & $<0.001$ \\
\hline Non-drinkers & $64,289(70.45)$ & $43,353(65.49)$ & $20,936(83.56)$ & \\
\hline Social drinkers & $9,448(10.35)$ & $7,794(11.77)$ & $1,654(6.60)$ & \\
\hline Heavy drinkers & $17,516(19.19)$ & $15,052(22.74)$ & $2,464(9.83)$ & \\
\hline Exercise status & & & & $<0.001$ \\
\hline Non-active & $80,103(87.73)$ & $58,376(88.18)$ & $21,727(86.55)$ & \\
\hline Active & $11,199(12.27)$ & $7,824(11.82)$ & $3,375(13.45)$ & \\
\hline House hold income level & & & & $<0.001$ \\
\hline $0-3$ & $26,560(28.64)$ & $19,859(29.52)$ & $6,701(26.32)$ & \\
\hline $4-7$ & $36,738(39.61)$ & $27,825(41.35)$ & $8,913(35.01)$ & \\
\hline $8-10$ & $29,447(31.75)$ & $19,600(29.13)$ & $9,847(38.67)$ & \\
\hline \multicolumn{5}{|c|}{ Modified NCEP-ATP III criteria } \\
\hline Abdominal obesity & $27,393(29 \cdot 54)$ & $9,553(14.20)$ & $17,840(70.07)$ & $<0.001$ \\
\hline Hypertriglyceridemia & $29,944(32.29)$ & $9,972(14.82)$ & $19,972(78.44)$ & $<0.001$ \\
\hline Low HDL-C level & $25,633(27.64)$ & $11,432(16.99)$ & $14,201(55.78)$ & $<0.001$ \\
\hline High blood pressure & $39,010(42.06)$ & $17,145(25 \cdot 48)$ & $21,865(85.88)$ & $<0.001$ \\
\hline Hyperglycemia & $28,217(30.42)$ & $10,817(16.08)$ & $17,400(68.34)$ & $<0.001$ \\
\hline
\end{tabular}

Values are presented as number (\%) or geometric mean \pm SD. Percentages may not sum to $100 \%$ because of missing data. Abdominal obesity, waist circumference $\geq 90 \mathrm{~cm}$ in men and $\geq 85 \mathrm{~cm}$ in women; hypertriglyceridemia, serum triglyceride $\geq 150 \mathrm{mg} / \mathrm{dL}$; low HDL-C level, HDL-C $<40 \mathrm{mg} / \mathrm{dL}$ in men and $<50 \mathrm{mg} / \mathrm{dL}$ in women; high blood pressure, blood pressure $\geq 130 / 85 \mathrm{mmHg}$ or current use of antihypertensive medication; hyperglycemia, serum glucose $\geq 100 \mathrm{mg} / \mathrm{dL}$ or current use of medication for diabetes. BMI, body mass index; SBP, systolic blood pressure; DBP, diastolic blood pressure; FBG, fasting blood glucose; TC, total cholesterol; TG, triglyceride; HDL-C, high density lipoprotein cholesterol; LDL-C, low density lipoprotein cholesterol; Cr, creatinine; AST, aspartate transaminase; ALT, alanine aminotransferase; $\gamma$ GT, gamma-glutamyl transpeptidase; NCEP-ATP, National Cholesterol Education Program-Adult Treatment Panel. 


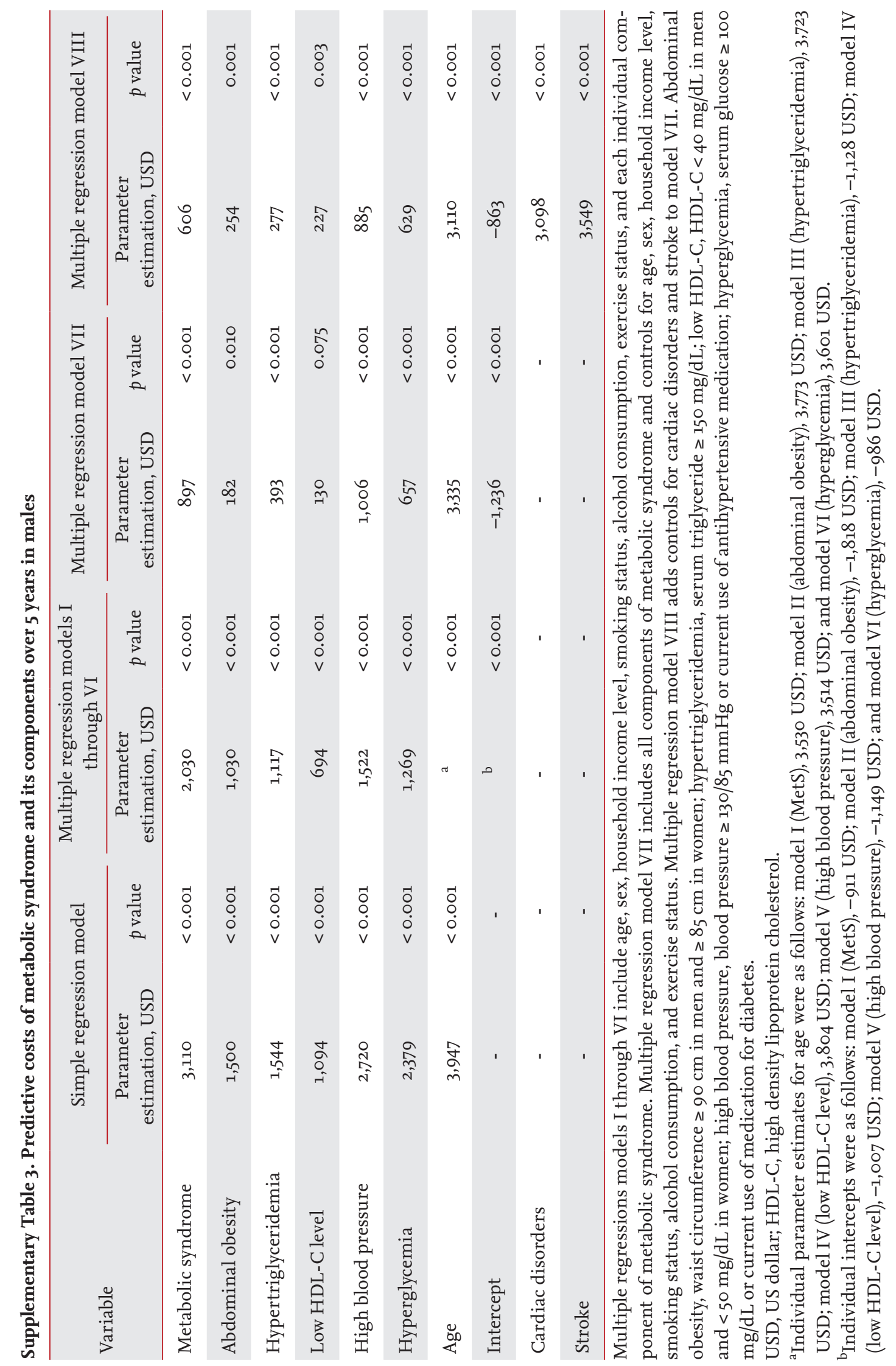




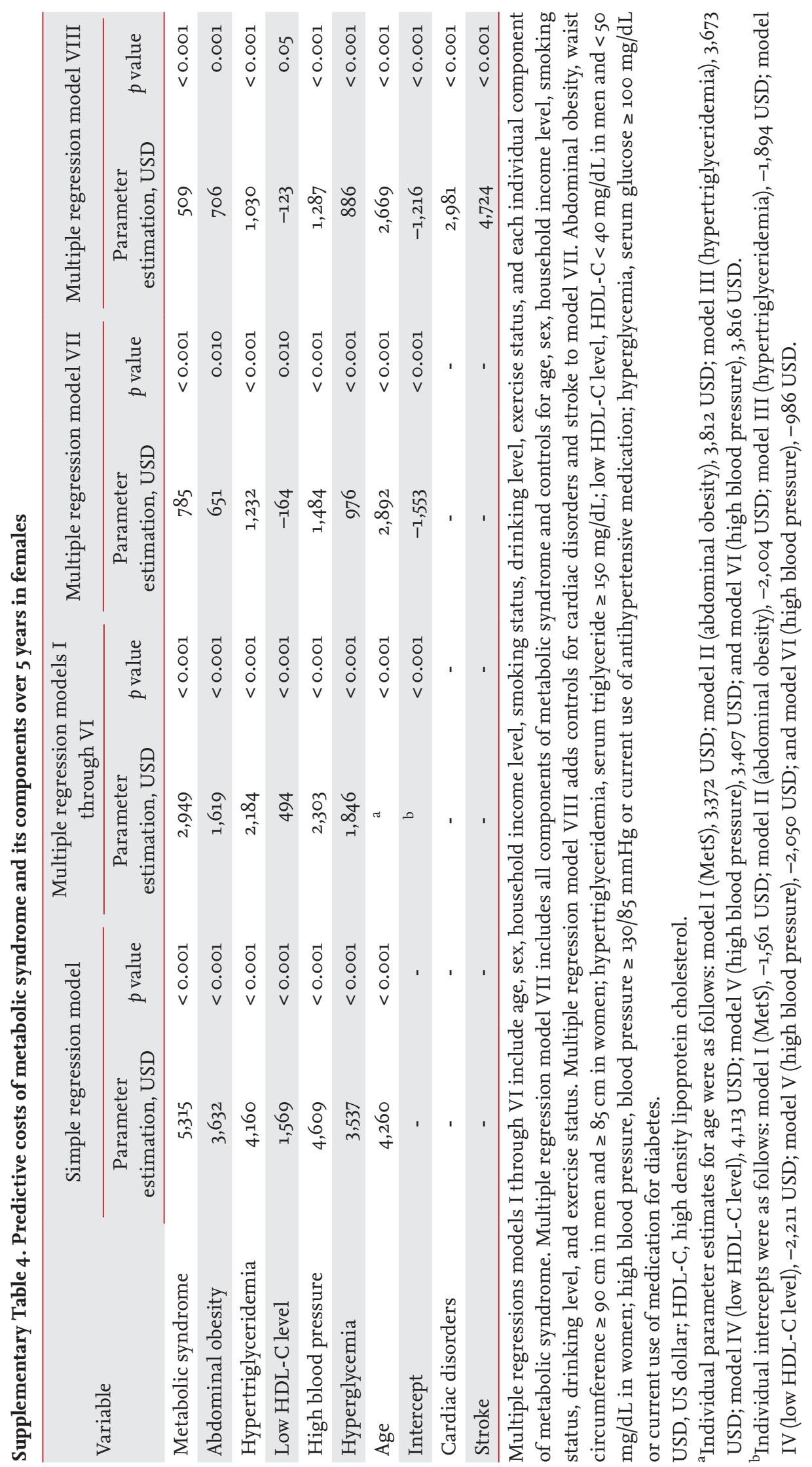

